\title{
Female and Kitchen Space
}

\author{
Hui Wang ${ }^{1,}$, Lixia Liang 2 ,b \\ ${ }^{1}$ School Of Political Science And Law University Of Jinan, Shandong 250022, China; \\ ${ }^{2}$ School Of Political Science And Law University Of Jinan, Shandong 250022, China; \\ a1175218674@qq.com, b川xia76@163.com
}

\begin{abstract}
Keywords: Feminist geography; Space; Kitchen; Male hegemony.
\end{abstract}
\begin{abstract}
Kitchen space and women have always been associated with each other. This article uses feminist geography criticism theory, from the perspective of kitchen space combining the Chinese contemporary feminist literature texts such as Kitchen, Double-sided Glue and Whitewater Green Vegetables, the author discusses the gender construction, female destiny, identity and anti-aphasia of Chinese women in the kitchen space: in the kitchen space, women face discourse rule from male hegemony, mental oppression of traditional women, and the difficult situation in which modern female invaders attack each other.
\end{abstract}

\section{Introduction}

From the gender declaration of Woolf "one's own house" to the Western cultural circle has a remarkable "space turn" in the second half of the twentieth Century, the feminist criticism theory and the cross discipline of human geography have made a breakthrough in the research of female literature by transforming its traditional one-way time examination into focusing on space problem. ${ }^{[1]}$ In the view of feminists, space a product of society, which is created by the relationship between social productivity and production, and serves as a symbolic capital of patriarchal society. Woolf believed that some public places and urban buildings seem to be neutral and objective, but when they are analyzed in the feminist perspective of gender space, obvious traces of patriarchal concept can be found in the urban space, and the characteristics of sex discrimination appear in the criticism of this female space(Woolf, 2010)

This paper attempts to reproduce the gender identity and power struggle in the spatial field through specific text interpretation and spatial analysis, focusing the research perspective on the kitchen, a private space filled with gender discrimination and binary opposition, revealing through the gender metaphor contained therein. ${ }^{[2]}$ Women are influenced by the cultural influence of the patriarchal value system and the abduction of male public consciousness. They have long been in a subordinate position and have been in a state of survival for a long time.

\section{The dance of the kitchen wearing ankles}

The small kitchen is not just an individual, simple housework space, but a microcosm of a modern society ${ }^{[2]}$ : it is a space field that reflects various social forces, and it is also a life theater for every living woman to perform daily(Lefebvre,1991). Lefebvre believes that space is the material reproduction of the construction of social order. The traditional society is dominated by men, and the arrangement of space is dominated by the concept of patriarchy. ${ }^{[3]} \mathrm{Home}$ is a place for rest and leisure for men, but a place for labor for women, and yet women's right to use space is ignored. From the perspective of social attributes, the kitchen is a typical "male supremacy space" ,in such an environment, the kitchen is further shaped into a woman's forbidden place. In short, the kitchen space is the main field in which women lose their main characteristics and are objectified in their life cycle as women. ${ }^{[4]}$

"The kitchen is the starting point and mooring place of a woman(Xu ,2013)." In the novel Kitchen, the contemporary female writer Xu Kun's place has clearly highlighted the relationship between women and the closed space of a kitchen for thousands of years: in a sense the kitchen is 
feminine, full of trivial, ordinary tones, but requires a tough character to handle all kinds of small things. ${ }^{[5]}$ As a woman who struggling on the edge of the patriarchal society, not only she is rejected by the social public space, but in the labor position of the kitchen, she plays the role of a cook while most men play the role of resource supervisor and controller, which make it become a physical course of cooking. Men helps producing women who meet social standards, and women only need to be responsible for producing food. As in the novel Kitchen, the heroine Zhi Zi, whose career is frustrated, has "not been willing to be a housewife for a lifetime." After already having a successful career, she was eager to hide back to the kitchen once betrayed by her and become a "woman" again rather than a "superwoman", reigniting a fire of obedience to men and families. In the kitchen of a painter named Song Ze, Zhi Zi shows her love to him in the kitchen language, and confirms her position of being sheltered, and belonging to this space. However, while Song Ze understood her meaning, he only wanted to involve emotionally and would not afford her love illusions and a promise of marriage. When she was sent home, numbly, she still had a kitchen garbage in her hand.

As a strong woman who has experienced a failed marriage and was tired of urban competition, $\mathrm{Zhi} \mathrm{Zi}$ expects a kitchen shared with her man, rather than a cage that only requires women to work without meaning. In this kind of kitchen, however, women need specific men, while men need only abstract women. Women who lose their self-identity can only dance alone with their ankles shackled.

\section{Fratricidal execution ground: two generations of women}

If women's aphasia in the kitchen space is caused by patriarchy, traditional women, as participants in this culture, act as accomplices to maintain the deformed gender order. The mother-in-law who represents traditional culture has multiple identities: she is the mother of the patriarchal representative and plays the role of the daughter-in-law of her own mother-in-law, which means she is the victim and as well as a implementer of the patriarchal system in the meantime. The novel Double-sided Glue writes a family tragedy caused by fighting between the in-laws.

Li Juan, the daughter-in-law, and her husband Ya Ping have a happy and sweet marriage life which became crumbling and the family contradictions escalated step by step because her mother-in-law suddenly broke into it. As a defender of traditional ideas, the mother-in-law maintains Ya Ping's status as the absolute authority of the family and attempts to transform Li Juan with her own ethical concepts and lifestyle; she believe that men are the root and center of women, men are going to make a living, and come back home for rest and entertainment; the value of women is to serve men and reproduce the next generation. Women should do more housework, and meals should be given to husbands and children first (women will only have their shares afterwords). These believes are completely in conflict with Li Juan's. With the contradiction between them increased day by day, the whole family was in chaos until one day the husband, Ya Ping, lost his temper in a quarrel and strangled Li Juan to death. The family shattered in the end.

Although her mother-in-law is a woman, the structures and values of the patriarchal system are deeply rooted in her bones. Their ideological concepts are the substitutes of the traditional Chinese patriarchal consciousness that has thousands of years history. Modern women emphasize the realization of self-worth, advocate equal and free love, and independent personality, and have extremely high requirements for quality of their marriage. It can be said that women in the kitchen have the same gender, but if their consciousnesses of gender and believes are different, their understandings of kitchen is different: kitchen is either a place for communication between women or a slain scene between two generations of women.

\section{Modern women's battlefield}

Unlike professional women like $\mathrm{Zhi} \mathrm{Zi}$ and $\mathrm{Li}$ Juan, some housewives are willing to protect love and live in seclusion. By combining female experience and kitchen language, expressing self-value in a dish, they make a small kitchen a feminine defense of family status and a culture of patriarchal 
culture. If cooking is a tactic, then the heroine in the female writer Pan Xiangli's short story Plainwater Green Vegetables was always trying to catch her man's stomach in kitchen. This housewife, whose name was not even mentioned in the book, buried herself in kitchen and she was so obsessed with cooking that it ignited her maternal instinct. She enjoyed gazing at her whole families eating at the dinner table. The good appetite of her families did not necessarily ensured that there would be an equal match in the erotic aspect of her marriage. Her husband was derailed, who spent his time separately in the two kitchen spaces (his wife's and his lover's) with simple home-cooked meal on his one hand, on the other side there were dishes that is full of emotion but has no real flavor. In the end, his lover came to his home, but it seems that she was already in the housewife's expectation. The housewife behaved still the same way as she usually did, with no chaos, the two of them just ate calmly and even "shared" their cooking tips and techniques with each other! What's more surprising was that the housewife told this "invader" of her family all her cooking techniques without reservation. ${ }^{[6]}$

At the end of the novel, when the man came home from his lover, a bowl of soup that looked exactly the same as usualy was placed in front of him. However, the wife did not love him anymore, and therefore the taste of the soup was unbearable with all her depression inside other than love. Even if modern housewives won this kitchen battle, there would only be two possibilities: one is to forgive their husbands' betrayal, and continue to surrender under the male hegemony; the other one is, to stop relying on men when marriage breaks down, and withdraw from the kitchen and go back to a public field where gender imbalance and survival anxiety are greater. However, if they are defeated in the kitchen, they will be abandoned by their traditional men, lose their dignities and social positions. Obviously, regardless of victory or defeat, if women want to be positively recognized by men or society, kitchen is a lost battlefield if they can not establish their individual positions.

\section{Conclusion}

After beauvoir having torn open the coat of gender imbalance, written the history of women in her book The Second Sex, and with Lefebvre having explored "the three spaces" in his masterpiece Production Of Space, the problem of female alienation has gradually deepened its existence from the philosophical literal discussion to the research field of sociology. Feminist geography criticism reflects on the space situation of women, tries to restore their nature that are repressed, and re-constructs women's self-identity. From the perspective of feminist geography criticism, this article discusses women's private space under the influence of male hegemony, and explains the relationship between gender discrimination and female destiny in a kitchen from three perspectives: male hegemony, traditional women and modern women. In kitchen, women have to suffer attacks from these three, for example double standards regarding male and female rights, male superiority, and gender discrimination, etc., which not only ruins womenmentally and physically, but also force them into a crisis of aphasia and being materialized. Female destiny has received more and more attention in the change of history and space, we expect women to live peacefully in space construction and have free and equal lives.

\section{References}

[1] Edward W.Soja, Third Space: Journey to Los Angeles and other real and imaginative places, Shanghai Education Publishing House, 2005.

[2] Wu Zhengzhong, The Dance of the Kitchen: A Survey of the Daily Life of the Body and Space, Union Press, 2010.

[3] Wu Ning, Criticism of Daily Life: Research on Lefebvre's Philosophical Thoughts, People's Publishing House, 2007. 
[4] Xu Shenglun, Xia Zhujiu, Wong Zhuzhong, Space, gender and power of traditional kitchen stoves, Zhejiang Journal, vol.4,2006.

[5] Xu Kun, North of Beijing, Kunlun Mountain Publishing House, 2013.

[6] Pan Xiangli,Whitewater Green Vegetable,Masterpieces Review,vol.11,2004. 